\title{
Accompaniment to healthcare visits: the impact of sensory impairment
}

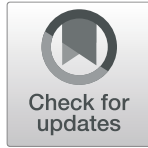

Nicholas S. Reed ${ }^{1,2^{*}}$ D, Lama Assi ${ }^{1,3}$, Emily Pedersen ${ }^{1}$, Yasmeen Alshabasy ${ }^{1}$, Ashley Deemer ${ }^{3}$, Jennifer A. Deal ${ }^{1,2}$, Amber Willink ${ }^{1,4}$ and Bonnielin K. Swenor ${ }^{2,3}$

\begin{abstract}
Background: Millions of older adults in the United States experience hearing, vision, and dual sensory impairment (concurring hearing and vision impairment) yet little research exists on their needs in interactions with the healthcare system. This piece aims to determine the use of accompaniment in healthcare interactions by persons with sensory impairment.

Methods: These cross-sectional analyses included data from the 2015 Medicare Current Beneficiaries Survey and survey weighting provided by Centers for Medicare and Medicaid Services. Adjusted odds of reporting accompaniment to healthcare visits and given reasons for accompaniment among United States Medicare beneficiaries with self-reported sensory impairment (hearing, vision, and dual sensory impairment) were examined.

Results: After excluding observations with missing data, 10,748 Medicare beneficiaries remained representing a 46 million total weighted nationally representative sample, of which $88.9 \%$ reported no sensory impairment, 5.52\% reported hearing impairment, 3.56\% reported vision impairment, and $0.93 \%$ reported dual sensory impairment. Those with vision impairment and dual sensory impairment had 2.139 (95\% confidence interval $[\mathrm{Cl}]=1.605-2.850$ ) and $2.703(\mathrm{Cl}=1.549-4.718)$ times the odds of reporting accompaniment to healthcare visits relative to those without sensory impairment. A secondary analysis suggests communication needs as the primary reason for accompaniment among persons with hearing loss, while those with vision impairment were more likely to indicate transportation needs.

Conclusions: Healthcare accompaniment is common for persons with sensory loss and healthcare systems should consider accommodations for and leveraging accompaniment to improve healthcare for persons with sensory impairments. In light of the current COVID-19 pandemic, as hospitals limit visitors to reduce the spread of infection, arrangements should be made to ensure that the communication and transportation needs of those with sensory impairment are not neglected.
\end{abstract}

Keywords: Hearing, Vision, Dual sensory impairment, Accompaniment, Companion

\footnotetext{
* Correspondence: Nreed9@jhmi.edu

${ }^{1}$ Cochlear Center for Hearing and Public Health, Johns Hopkins University

Bloomberg School of Public Health, 2024 E. Monument Street, Baltimore, MD 21205, USA

2Department of Epidemiology, Johns Hopkins University Bloomberg School of Public Health, Baltimore, MD, USA

Full list of author information is available at the end of the article
}

(c) The Author(s). 2020 Open Access This article is licensed under a Creative Commons Attribution 4.0 International License, which permits use, sharing, adaptation, distribution and reproduction in any medium or format, as long as you give appropriate credit to the original author(s) and the source, provide a link to the Creative Commons licence, and indicate if changes were made. The images or other third party material in this article are included in the article's Creative Commons. licence, unless indicated otherwise in a credit line to the material. If material is not included in the article's Creative Commons licence and your intended use is not permitted by statutory regulation or exceeds the permitted use, you will need to obtain permission directly from the copyright holder. To view a copy of this licence, visit http://creativecommons.org/licenses/by/4.0/ The Creative Commons Public Domain Dedication waiver (http://creativecommons.org/publicdomain/zero/1.0/) applies to the data made available in this article, unless otherwise stated in a credit line to the data. 


\section{Background}

\section{Sensory impairment}

Vision and hearing impairment are highly prevalent, chronic conditions which disproportionately affect older adults [1]. In the United States, vision impairment impacts approximately 14 million individuals 12 years and older, of which approximately 3 million would remain impaired even with refractive correction [2]. Similarly, estimates suggest that hearing impairment, defined as a mild or greater hearing loss using World Health Organization criteria, impacts 38 million Americans and increases in prevalence with age such that two-thirds of Americans over age 70 years [3, 4]. A small and often overlooked subset is those with dual sensory impairment, concurrent hearing and vision impairment, which affects 1 in 9 , or $11.3 \%$, of Americans 80 years or older [5]. As the United States population ages, these numbers are expected to increase $[6,7]$.

Once considered benign aspects of aging, recent literature has emphasized the public health importance of sensory impairment. Sensory impairment is independently associated with numerous negative health outcomes in older adults, including cognitive decline, dementia, falls, and functional decline and loneliness [8-13]. Despite consequences outlined above, adoption and pursuit of sensory care remains low: only $20-30 \%$ of persons with hearing impairment own and use hearing aids while less than $50 \%$ of Medicare beneficiaries with vision impairment have had an annual eye exam $[14,15]$.

Concurrent vision and hearing impairment may exacerbate negative health associations. Dual sensory impairment presents a unique challenge by removing sensory substitution compensatory strategies (i.e. reliance upon visual cues in the presence of hearing impairment and auditory cues in the presence of visual impairment) [16]. There is a paucity of research on adults with dual sensory impairment. However, available evidence suggests those with dual sensory impairment experience compounded psychosocial, psychological and functional effects compared to those with either hearing or visual impairment only [17].

\section{Sensory impairment in healthcare}

Recent research has focused on how sensory impairment impacts healthcare specific outcomes. In a study of matched adults with and without vision loss who were hospitalized for common illnesses, Medicare beneficiaries with severe vision loss had, on average, $4 \%$ longer lengths of stay, $22 \%$ higher odds of 1 -month readmission, and $12 \%$ higher mean costs of healthcare services during hospitalization and 90 days after discharge. Similar associations were seen among adults with commercial health insurance, where those with severe vision loss had a $4 \%$ longer length of stay, 32\% higher odds of readmission, and $8 \%$ higher costs [18]. Similarly, in a study of propensity-matched adults with and without hearing loss, adults with hearing loss accumulated, on average, $\$ 22,434$ (95\% CI, \$18,219-\$26,648) more in healthcare expenditures over a 10-year period. In addition, adults with hearing loss experienced a $47 \%$ higher rate of hospitalization, $44 \%$ higher risk of 30 -day readmission, and spend, on average, 2.5 days longer during an inpatient stay over a 10-year period [19]. Increased healthcare utilization may contribute to suggested poorer perceived satisfaction with care among those with sensory loss [20, 21].

Sensory impairment may negatively impact and limit communication, including patient-provider communication. When navigating health systems, individuals with vision or hearing impairment face barriers to effective communication which is a pillar of patient-centered care [22]. For clinicians, communication limitations with patients could increase the time, effort and frustration associated with providing adequate care. For those with sensory impairment, inadequate communication with healthcare providers could increase the likelihood of misunderstanding medical information, reduce treatment adherence, lower patient satisfaction, and can result in poorer clinical outcomes or even accidental injury [23].

\section{Accompaniment in healthcare}

In the United States, $20-50 \%$ of older adult patients are accompanied by a companion to their medical visits [24]. Importantly, in response to deficits in care quality and rising healthcare costs, there is a growing appreciation for patient-centered care and patient-provider communication and the concept of "patient-family-physician" partnerships. Previous studies on accompaniment in healthcare settings have demonstrated that the presence of companions may positively impact patient understanding, information recall and engagement in medical decision-making $[25,26]$. However, there is limited research on the patterns of accompaniment for older adults with sensory impairment despite their unique communication and physical (i.e., transportation) barriers faced in accessing and interacting with the healthcare system. For older adult patients with sensory impairment, accompaniment may be particularly important to optimal patient care. To our knowledge, no previous studies have examined whether sensory impairment is associated accompaniment to physician visits in a nationally representative sample of older adults. This study investigated the patterns of and reasons for accompaniment to physician visits of Medicare beneficiaries with hearing impairment, vision impairment, and dual sensory impairment compared to those without sensory impairment. 


\section{Methods}

\section{Data source}

This cross-sectional, retrospective cohort study was conducted using de-identified data from the Medicare Current Beneficiary Survey (MCBS) 2015 public use file [27]. The MCBS is an annual nationally-representative survey of Medicare beneficiaries which collects demographic, socioeconomic, medical and health status, healthcare utilization, healthcare access, and healthcare satisfaction data. Medicare is the United States federal health insurance program for all adults aged 65 and older as well as adults younger than 65 with disabilities and end stage renal disease [28]. In 2015, a reported 55, 496,222 individuals were enrolled in Medicare [29]. Of these enrollees, 12,311 Medicare beneficiaries participated in the 2015 MCBS. Due to the public availability and de-identified nature of the data set, this study was exempt from institutional review board.

\section{Outcome variables}

The primary and secondary outcomes of this study were accompaniment to the doctor's office and reasons for accompaniment, respectively. Participants were first asked if they had a usual place of care when sick or in need of medical advice. Those who noted a usual place of care were asked: "Do you usually have someone accompany you there [usual place of care]?" - "No" or "Yes". In follow-up, participants were asked "What are the reasons this person accompanies you there? What does this person do?" They were then given a list of responses and asked to check all that apply. The responses included: "writes down what the doctor says/records instructions/ takes notes/remembers," "gives information/explains medical conditions or needs to doctor," "explains doctor's instructions to [participant]," "asks questions," "translates language," "schedules appointments," "nothing/keeps company/sits with [participant]/moral support," "transportation," “[participant] needs physical assistance, and "other."

\section{Exposure and covariates}

Medicare beneficiaries were categorized into sensory impairment categories based on self-report questions. Participants were asked, "Which statement best describes your hearing [with a hearing aid]?" - "No trouble", "A little trouble", and "A lot of trouble" and "Which statement best describes your hearing [with a hearing aid]?" "No trouble", "A little trouble", and "A lot of trouble" and "Which statement best describes your vision [while wearing glasses]?" - "No trouble", "A little trouble", and "A lot of trouble." Participants were than categorized according to responses to these questions: (1) no perceived sensory impairment, (2) perceived hearing impairment only, (3) perceived vision impairment only, and (4) perceived dual sensory impairment. Participants were classified as having perceived dual sensory impairment if they replied "a lot of trouble" to both questions. They were classified as having perceived hearing impairment only if they replied "a lot of trouble" to only the hearing question and classified as having perceived vision impairment only if they replied "a lot of trouble" to only the vision question. All other participants were classified as having no perceived sensory impairment. Limiting to "a lot of trouble" was selected to capture participants who are significantly impacted and impaired by sensory impairment.

Several factors were identified as potential confounders. Demographic variables included age (categorized as younger than 65,65 to 74 years old, and older than 75 years), self-reported race (Non-Hispanic White, Non-Hispanic Black, Hispanic, and other), and gender (male or female). Further, we included sociodemographic variables including educational attainment (less than high school, high school or vocational/technical/ business degree, more than high school), income (less than $\$ 25,000$ or greater than or equal to $\$ 25,000)$, dual Medicaid-Medicare eligibility status (nondual, full dual, partial dual, and qualified Medicare beneficiary dual), and marital status (married or not married/widowed/divorced). Health-related factors included self-perceived general health status compared to others of the same age (excellent, very good, good, fair, or poor), selfreported depression based on ever being told by a doctor (yes or no), and difficulty walking $1 / 4$ mile (no difficulty, little difficulty, some difficulty, a lot of difficulty, or unable to do it).

\section{Statistical analysis}

Survey weights, supplied by Centers for Medicare and Medicaid Services, were applied to account for the design of the MCBS including stratification, clustering, multiple stages of selection, and disproportionate sampling. Descriptive and univariate chi-square analyses were used to identify trends and explore associations between sensory impairment categories, covariates, and outcome variables. Multivariate logistic regression was used to model the association between perceived sensory impairment and odds of accompaniment after adjusting for confounding variables. A model building approach was utilized using Akaike Information Criterion to assess models. The $\beta$ coefficients (log-odds) were converted into odds ratios for ease of interpretation. Significance testing for all analyses was 2-sided with a type I error of 0.05. Subjects with missing data were excluded from analyses. Sensitivity analysis excluding those with a Medicare status code indicating disabled (i.e., receiving 
Medicare for reasons other than age) was completed. The statistical software used was Stata 15 (StataCorp, College Station, TX).

\section{Results}

\section{Demographic characteristics}

Following exclusion of those with missing data, the final unweighted sample included 10,748 Medicare Beneficiaries. In a nationally representative weighted sample of $46,029,364$ Medicare beneficiaries in 2015, 41,421,015 (88.9\%) reported no sensory impairment, 2,542,752.2 (5.52\%) reported hearing impairment only, 1,637,622.5 (3.56\%) reported vision impairment only, and 427,974.7 (0.93\%) reported dual sensory impairment. Table 1 displays the weighted demographic characteristics of this sample. Among Medicare beneficiaries without sensory impairment, $32.59 \%$ reported having someone accompany them to physician visits in 2015, compared to $65.52 \%$ of those with vision impairment, $43.46 \%$ of those with hearing impairment, and $72.11 \%$ of those with dual sensory impairment. A higher proportion of Medicare beneficiaries with dual sensory impairment (59.85\%) and hearing impairment $(45.23 \%)$ were 75 years and older than those with vision impairment (35.96\%) and no sensory impairment (33.33\%). A higher proportion of those with vision impairment identified as Non-Hispanic Black (13.72\%) or Hispanic (15.38\%) relative to those with no sensory impairment, hearing impairment, and dual sensory impairment. Relative to individuals without sensory impairment, Medicare beneficiaries with sensory impairment (hearing, vision, or dual-sensory impairment) reported a lower proportion of individuals with more than a high school diploma, a higher proportion of persons reporting income of less than $\$ 25,000$ a year, and lower proportions of married individuals. A higher proportion of participants with dual sensory impairment reported inability to walk a quarter mile $(43.70 \%)$ and poor health relative to others their age $(19.31 \%)$ compared to those with hearing impairment $(26.39,12.16 \%)$, vision impairment $(36.12,23.98 \%)$, and those with no sensory impairment (13.16, 5.97\%).

\section{Odds of accompaniment}

Table 2 displays the odds of accompaniment by demographic and health characteristics of the weighted sample. Relative to Medicare Beneficiaries without sensory impairment, those with hearing impairment had similar odds of accompaniment (odds ratio $[\mathrm{OR}]=1.043$; 95\% confidence interval $[\mathrm{CI}]=0.841-1.293 ; p=0.698)$. However, those with vision impairment $(\mathrm{OR}=2.139 ; \mathrm{CI}=$ $1.605-2.850 ; p=0.000)$ and dual sensory impairment $(\mathrm{OR}=2.703 ; \mathrm{CI}=1.549-4.718 ; p=0.001)$ had more than 2-times the odds of reporting accompaniment than those without sensory impairments. Compared with
Medicare beneficiaries 64 years and younger, those $65-$ 74 years of age had half the odds to be accompanied $(\mathrm{OR}=0.544 ; \mathrm{CI}=0.440-0.673 ; p=0.000)$, while those 75 years and older were more likely to report accompaniment $(\mathrm{OR}=1.382 ; \mathrm{CI}=1.163-1.643 ; p=0.000)$. Compared to non-Hispanic White Medicare beneficiaries, non-Hispanic Black beneficiaries $(\mathrm{OR}=1.221 ; \quad \mathrm{CI}=$ 0.999-1.492; $p=0.051)$, Hispanic beneficiaries (OR $=$ 1.65; $\mathrm{CI}=1.376-1.979 ; \mathrm{p}=0.000)$ and beneficiaries who reported 'other' for race $(\mathrm{OR}=1.410 ; \mathrm{CI}=1.113-1.786$; $p=0.005)$ had greater odds of accompaniment. No difference in odds was found between male and female beneficiaries. Higher income and more education were associated with reduced odds of accompaniment. Married Medicare beneficiaries had higher odds of accompaniment $\quad(\mathrm{OR}=2.789 ; \quad \mathrm{CI}=2.465-3.156 ; \quad p=0.000)$ relative to those who were not married. Physical ability appeared to be strongly associated with odds of accompaniment. Indeed, compared to Medicare beneficiaries who reported no difficulty walking one-quarter mile, those who reported a lot of difficulty walking onequarter mile $(\mathrm{OR}=2.360 ; \mathrm{CI}=1.887-2.951 ; p=0.000)$ or being unable to do this task $(\mathrm{OR}=3.524 ; \mathrm{CI}=2.949$ 4.212; $\mathrm{p}=0.000$ ) reported higher odds of accompaniment. Similarly, those who reported poor health had higher odds of accompaniment relative to those in excellent self-reported health.

\section{Reasons for accompaniment}

Table 3 displays the reasons for accompaniment among Medicare beneficiaries who indicated they were accompanied to healthcare visits by sensory impairment. In general, within each reason for accompaniment a higher percentage of persons with dual sensory impairment identified positively with the reason relative to those with no sensory impairment and/or those with hearing or vision impairment (note: participants could identify multiple reasons for accompaniment). When comparing those with hearing loss and those with vision loss relative to one another, a higher percentage of Medicare beneficiaries with hearing impairment indicated communication-related reasons for accompaniment, while a higher percentage of those with vision impairment indicated physical-related reasons for accompaniment. Indeed, $55.38 \%$ of beneficiaries with hearing impairment reported someone accompanying them to take notes compared with only $38.2 \%$ of beneficiaries with vision impairment. Similar trends were seen when the reason was explaining things to the doctor (53.77\% vs. $42.93 \%)$, explaining instructions (47.26\% vs. $36.76 \%)$, and asking questions ( $55.34 \%$ vs. $40.29 \%)$. However, Medicare beneficiaries with hearing impairment were less likely to report transportation as a reason for accompaniment than those with vision impairment, 
Table 1 Demographic and Socioeconomic Characteristics of Medicare Beneficiaries by Self-Reported Sensory Impairment

\begin{tabular}{|c|c|c|c|c|}
\hline \multirow[b]{3}{*}{ Variable } & \multirow[b]{2}{*}{ No Sensory Impairment } & \multicolumn{3}{|c|}{ Self-Reported Sensory Impairment } \\
\hline & & Hearing Impairment & Vision Impairment & Dual Sensory Impairment \\
\hline & N (\%) & N (\%) & N (\%) & N (\%) \\
\hline \multicolumn{5}{|l|}{ Unadjusted sample } \\
\hline$(N=10,748)$ & $9524(88.61 \%)$ & $668(6.22 \%)$ & $435(4.05 \%)$ & $121(1.13 \%)$ \\
\hline \multicolumn{5}{|l|}{ Weighted sample (In Millions) } \\
\hline$(N=46.03)$ & $41.42(89.99 \%)$ & $2.54(5.52 \%)$ & $1.64(3.56 \%)$ & $0.43(0.93 \%)$ \\
\hline \multicolumn{5}{|l|}{ Age (years) } \\
\hline 64 and younger & $6.20(14.98 \%)$ & $0.39(15.27 \%)$ & $0.49(29.88 \%)$ & $0.081(18.98 \%)$ \\
\hline $65-74$ & $21.41(51.69 \%)$ & $1.00(39.5 \%)$ & $0.56(34.16 \%)$ & $0.09(21.17 \%)$ \\
\hline 75 and older & $13.80(33.33 \%)$ & $1.15(45.23 \%)$ & $0.59(35.96 \%)$ & $0.26(59.85 \%)$ \\
\hline \multicolumn{5}{|l|}{ Gender } \\
\hline Female & $23.11(55.79 \%)$ & $1.13(44.4 \%)$ & $1.02(62.28 \%)$ & $0.23(53.72 \%)$ \\
\hline \multicolumn{5}{|l|}{ Race } \\
\hline Non-Hispanic White & $31.28(75.51 \%)$ & $2.05(80.48 \%)$ & $1.00(61.1 \%)$ & $0.31(71.69 \%)$ \\
\hline Non-Hispanic Black & $3.89(9.38 \%)$ & $0.13(4.98 \%)$ & $0.22(13.72 \%)$ & $0.02(4.94 \%)$ \\
\hline Hispanic & $3.47(8.38 \%)$ & $0.17(6.78 \%)$ & $0.25(15.38 \%)$ & $0.04(9.68 \%)$ \\
\hline Other & $2.79(6.73 \%)$ & $0.20(7.77 \%)$ & $0.16(9.79 \%)$ & $0.06(13.68 \%)$ \\
\hline \multicolumn{5}{|l|}{ Educational attainment } \\
\hline Less than 9th grade & $6.16(14.87 \%)$ & $0.60(23.64 \%)$ & $0.45(27.72 \%)$ & $0.17(39.03 \%)$ \\
\hline High school or vocational degree & $14.42(34.82 \%)$ & $1.00(39.37 \%)$ & $0.72(43.46 \%)$ & $0.15(34.04 \%)$ \\
\hline More than high school & $20.84(50.30 \%)$ & $0.94(36.99 \%)$ & $0.47(28.82 \%)$ & $0.12(26.93 \%)$ \\
\hline \multicolumn{5}{|l|}{ Income } \\
\hline Less than $\$ 25,000$ & $15.22(36.74 \%)$ & $1.10(43.35 \%)$ & $0.96(58.52 \%)$ & $0.30(71.06 \%)$ \\
\hline \multicolumn{5}{|l|}{ Marital Status } \\
\hline Married & $23.07(55.71 \%)$ & $1.35(53.02 \%)$ & $0.72(43.99 \%)$ & $0.13(30.40 \%)$ \\
\hline \multicolumn{5}{|l|}{ Difficulty walking $1 / 4$ mile } \\
\hline No difficulty & $23.75(57.33 \%)$ & $0.86(33.67 \%)$ & $0.39(24.09 \%)$ & $0.06(13.80 \%)$ \\
\hline Little difficulty & $4.48(10.82 \%)$ & $0.23(8.97 \%)$ & $0.13(8.05 \%)$ & $0.03(7.72 \%)$ \\
\hline Some difficulty & $4.32(10.43 \%)$ & $0.41(16.21 \%)$ & $0.27(16.23 \%)$ & $0.08(19.10 \%)$ \\
\hline A lot of difficulty & $3.42(8.26 \%)$ & $0.38(14.77 \%)$ & $0.25(15.51 \%)$ & $0.07(15.67 \%)$ \\
\hline Unable to do it & $5.45(13.16 \%)$ & $0.67(26.39 \%)$ & $0.59(36.12 \%)$ & $0.19(43.70 \%)$ \\
\hline \multicolumn{5}{|l|}{ General health } \\
\hline Excellent & $7.46(18 \%)$ & $0.20(7.93 \%)$ & $0.10(6.01 \%)$ & $0.02(5.66 \%)$ \\
\hline Very good & $12.61(30.45 \%)$ & $0.56(22.18 \%)$ & $0.24(14.49 \%)$ & $0.04(10.34 \%)$ \\
\hline Good & $1.23(29.66 \%)$ & $0.81(31.74 \%)$ & $0.38(22.95 \%)$ & $0.13(31.47 \%)$ \\
\hline Fair & $6.59(15.91 \%)$ & $0.66(26 \%)$ & $0.53(32.57 \%)$ & $0.14(33.22 \%)$ \\
\hline Poor & $2.47(5.97 \%)$ & $0.31(12.16 \%)$ & $0.39(23.98 \%)$ & $0.08(19.31 \%)$ \\
\hline \multicolumn{5}{|l|}{ Medicare Medicaid dual eligibility } \\
\hline Non dual & $34.79(83.99 \%)$ & $2.04(80.38 \%)$ & $1.05(64.02 \%)$ & $0.29(67.42 \%)$ \\
\hline Full dual & $4.33(10.45 \%)$ & $0.29(11.44 \%)$ & $0.44(26.57 \%)$ & $0.09(21.12 \%)$ \\
\hline Partial dual & $1.31(3.15 \%)$ & $0.13(5.29 \%)$ & $0.06(3.82 \%)$ & $0.02(5.76 \%)$ \\
\hline QMB dual & $1.00(2.41 \%)$ & $0.07(2.89 \%)$ & $0.09(5.58 \%)$ & $0.02(5.70 \%)$ \\
\hline \multicolumn{5}{|l|}{ Depression } \\
\hline Diagnosed & 11.55 (27.89\%) & $0.89(34.98 \%)$ & $0.79(48.07 \%)$ & $0.21(48.56 \%)$ \\
\hline \multicolumn{5}{|c|}{ Does someone accompany to doc office } \\
\hline Yes & 13.50 (32.59\%) & $1.11(43.46 \%)$ & $1.07(65.52 \%)$ & $0.31(72.11 \%)$ \\
\hline
\end{tabular}


Table 2 Odds of accompaniment of Medicare Beneficiaries by Self-Reported Sensory Impairment

\begin{tabular}{l} 
Variable \\
\hline Sensory impairment \\
No sensory impairment \\
Hearing impairment only \\
Vision impairment only \\
Dual sensory impairment \\
Age (years)
\end{tabular}

64 and younger

65-74

75 and older

\section{Gender}

Male

Female

\section{Race}

Non-Hispanic White

Non-Hispanic Black

Hispanic

Other

\section{Educational attainment}

Less than 9th grade

High school or vocational, degree

More than high school

\section{Income}

Less than $\$ 25,000$

Greater or equal to $\$ 25,000$

\section{Marital Status}

Not married

Married

\section{Difficulty walking $1 / 4$ mile}

$$
\begin{aligned}
& \text { No difficulty } \\
& \text { Little difficulty } \\
& \text { Some difficulty } \\
& \text { A lot of difficulty } \\
& \text { Unable to do it }
\end{aligned}
$$

\section{General health}

Excellent

Very good

Good

Fair

Poor

\section{Medicare Medicaid dual eligibility}

Non-dual

Full dual

Partial dual

\section{Odds Ratio}

(95\% Confidence Interval)

Standard Error

P-Value

REF

$1.043(0.841-1.293)$
$2.139(1.605-2.850)$

0.113

0.698

2.703 (1.549-4.718)

0.310

0.000

0.759

0.001

REF

$0.544(0.440-0.673)$

0.058

0.000

$1.382(1.163-1.643)$

0.120

0.000

REF

$1.063(0.942-1.200)$

0.065

0.316

REF

$1.220(0.999-1.492)$

0.123

0.051

$1.650(1.376-1.979)$

0.151

0.000

1.410 (1.113-1.786)

0.168

0.005

REF

$0.763(0.643-0.907)$

0.066

0.002

$0.499(0.420-0.594)$

0.044

0.000

REF

$0.758(0.652-0.883)$

0.058

0.000

REF

$2.789(2.465-3.16)$

0.174

0.000

REF

1.449 (1.190-1.765)

0.144

0.000

1.364 (1.135-1.639)

0.126

0.001

$2.360(1.887-2.951)$

0.266

0.000

3.524 (2.949-4.212)

0.317

0.000

REF

1.303 (1.095-1.550)

0.114

0.003

1.647 (1.388-1.954)

0.142

0.000

$2.116(1.722-2.601)$

0.220

0.000

$2.672(1.941-3.678)$

0.430

0.000

REF

$1.722(1.388-2.135)$

0.187

0.000

1.351 (1.004-1.816)
0.202 
Table 2 Odds of accompaniment of Medicare Beneficiaries by Self-Reported Sensory Impairment (Continued)

\begin{tabular}{llll}
\hline Variable & $\begin{array}{l}\text { Odds Ratio } \\
\text { (95\% Confidence Interval) }\end{array}$ & Standard Error & P-Value \\
\hline QMB dual & $1.271(0.889-1.817)$ & 0.229 & \\
Depression & & & \\
Never been diagnosed & REF & 0.185 \\
Diagnosed & $0.945(0.831-1.075)$ & 0.061 & 0.389 \\
\hline
\end{tabular}

$60.51 \%$ compared to $80.47 \%$ respectively. Additionally, a lower percentage of Medicare beneficiaries with hearing impairment reported assistance with ADLs as a reason for accompaniment (19.41\% vs. 28.34\%). Notably, accompaniment for translation was similar regardless of sensory loss status or type.

\section{Discussion}

Our study demonstrates that in a model adjusted for demographic and health factors, Medicare beneficiaries with vision impairment and dual sensory impairment have relatively high odds of reporting being accompanied by a companion to healthcare visits relative to without sensory impairment, even after accounting for potential confounders. When examining the reasons indicated for accompaniment by sensory impairment status and type, a higher percentage of those with hearing impairment report communication-related reasons for accompaniment relative to those with vision impairment. Our study is limited by MCBS survey questions, and its respondents' interpretation, memory, veracity and accuracy. The interpretation of MCBS survey questions about accompaniment may have included companions who remained outside of examination rooms. Thus, our findings do not account for the presence or nature of the accompaniment during the patient-physician interaction specifically, but instead more broadly describe accompaniment to physician visits. These results have implications for healthcare quality planning and adaption to accommodate for the elevated accompaniment needs of Medicare beneficiaries with sensory impairment.

To our knowledge this is the first analysis of accompaniment to physician visits by sensory impairment in a nationally representative sample. A large proportion of Medicare beneficiaries with sensory loss report accompaniment to healthcare visits relative to those without sensory loss. Much of the previous work has focused on and highlighted the beneficial aspects of accompaniment to healthcare visits including patient engagement and healthcare outcomes $[25,26,30]$. Notably, among demographic covariates, our results are consistent with previous studies which have described older adults who report accompaniment to physician visits as older, less educated by degree attainment, and poorer in health [25, 26]. The relatively high rate of accompaniment among those who identify as Hispanic may be due to language barriers [31]. Another first-in-kind finding is the difference in the reasons indicated for accompaniment, especially between Medicare beneficiaries with hearing impairment only versus vision impairment only. A higher proportion of those with hearing impairment reported communication-related reasons while a higher proportion of those with vision impairment reported physical barriers such as transportation or ADLs as reason for accompaniment. These results are consistent with previous studies indicating hearing impairment's limitations on communication and vision impairment's association with reduced mobility [32, 33], and access to care barriers due to transportation issues [34].

By focusing on the association with healthcare accompaniment and reasons for accompaniment among those with sensory loss, this study highlights an oftenoverlooked population. In particular, this piece contributes to the literature by representing persons with dual sensory impairment as vision and hearing are sometimes treated and discussed as independent of one another despite significant overlap among older adults [5]. While accompaniment is considered beneficial, the relatively high odds among persons with hearing, vision, and dual sensory impairment may indicate that the healthcare system does not appropriately accommodate persons with sensory impairment. Communication is fundamental to patient-centered healthcare [35] and ability to access healthcare relies on ability to interact with environments. As the availability of primary family resources and informal caregivers is expected to decrease with time [36], more older adults might find themselves without a companion. Healthcare systems could take steps such as implementing communication training programs specific to sensory deficits [37] and taking vision impairment into consideration when designing healthcare environments (e.g., large print signage, auditory cues).

In addition, companions are a potentially valuable quality of care resource for persons with sensory impairment [26]. Previous studies on accompaniment during patient-physician encounters suggest that companions may facilitate physician and patient understanding when they are more verbally active and engage in autonomy-enhancing behaviors [25, 26, 30, 38]. These helpful companion behaviors include 
Table 3 Reason indicated for Accompaniment Among Medicare Beneficiaries who reported Accompaniment by Self-Reported Sensory Impairment

\begin{tabular}{lllll}
\hline & $\begin{array}{l}\text { No Sensory } \\
\text { Impairment } \\
\text { Variable }\end{array}$ & $\begin{array}{l}\text { Self-Reported Sensory Impairment } \\
\text { Impairment }\end{array}$ & $\begin{array}{l}\text { Vision } \\
\text { Impairment }\end{array}$ & $\begin{array}{l}\text { Dual sensory } \\
\text { Impairment }\end{array}$ \\
\hline Someone accompanies to take notes & $\mathbf{N}$ (In Millions) (\%) & $\mathbf{N}$ (In Millions) (\%) & N (In Millions) (\%) & N (In Millions) (\%) \\
Someone accompanies to explain things to doctor & $5.50(40.73 \%)$ & $0.61(55.38 \%)$ & $0.41(38.2 \%)$ & $0.18(58.5 \%)$ \\
Someone accompanies to explain instructions & $4.04(29.94 \%)$ & $0.52(47.26 \%)$ & $0.39(36.76 \%)$ & $0.22(57.6 \%)$ \\
Someone accompanies to ask questions & $5.40(40 \%)$ & $0.61(55.34 \%)$ & $0.43(40.29 \%)$ & $0.20(65.39 \%)$ \\
Someone accompanies to translate & $0.48(3.5 \%)$ & $0.04(3.22 \%)$ & $0.03(3.25 \%)$ & $0.01(3.18 \%)$ \\
Someone accompanies to schedule appointment & $3.07(22.78 \%)$ & $0.33(29.5 \%)$ & $0.30(28.07 \%)$ & $0.13(43.73 \%)$ \\
Someone accompanies for moral support & $5.32(39.41 \%)$ & $0.35(31.68 \%)$ & $0.31(29.23 \%)$ & $0.06(18.82 \%)$ \\
Someone accompanies for transportation & $7.59(56.27 \%)$ & $0.67(60.51 \%)$ & $0.86(80.47 \%)$ & $0.25(82.14 \%)$ \\
Someone accompanies to assist with ADLs & $1.89(14 \%)$ & $0.21(19.41 \%)$ & $0.30(28.34 \%)$ & $0.10(32.67 \%)$ \\
Someone accompanies for another reason & $0.77(5.68 \%)$ & $0.06(5.44 \%)$ & $0.02(1.42 \%)$ & $0.03(5.43 \%)$ \\
\hline
\end{tabular}

recording physician instructions, providing information on the patient's condition, asking for clarification, and offering further explanation when confusion arises. However, companions have also been shown to engage in disruptive behaviors, like interrupting or criticizing the patient, which deter patient-participation in medical decision-making [39]. Given that companionship among persons with sensory loss may be particularly important to ensure high-quality patient-provider communication and the high prevalence of accompaniment among persons with sensory loss, healthcare systems could focus on quality initiatives aimed at educating companions about the needs of persons with sensory lost to help facilitate the exchange of information.

In the context of the ongoing coronavirus disease 2019 (COVID-19) pandemic, when banning or limiting visitors at healthcare facilities may be necessary to control the spread of infection [40], the healthcare experience of those with sensory loss may be particularly affected. Facilitating telecommunication with companions may be important to provide high quality patient-centered care, and current talks about long-term changes to the delivery of care should include solutions for those who may be relying on their companions to have access to care or communicate with their providers.

The findings from this study have limitations. The results are limited in generalizability to only Medicare beneficiaries. Moreover, the cross-sectional nature of the data do not allow for the exploration of temporality. The MCBS questionnaire design is also limited. On the MCBS, there are no questions to understand neither the actions of companions nor the immediate implications of accompaniment. Thus, those measures are beyond the scope of this study. The survey's phrasing of "usually accompanied to your medical visit" may have been interpreted to include companions regardless of whether they join the medical encounter or instead remain in vehicles or waiting rooms. Moreover, the MCBS measures sensory impairment by self-report which may have resulted in an underestimation of the number of individuals with hearing and/or vision impairment. Thus, these findings are limited by the interpretation of the MCBS questions by respondents. Lastly, these findings are limited to routine medical encounters among older adults who report having a usual source of care and do not include those without usual sources of care who may be a particularly vulnerable population.

Further well-designed studies are needed to determine whether companions of those with sensory impairment are playing an active role during patient-provider encounters, and whether accompaniment by family, friends, caregiver modifies previously described associations such as poorer patient satisfaction and higher readmission rates. Moreover, qualitative research is needed to understand the perceptions of navigating, accessing and communicating in the healthcare setting among people with sensory impairments, and to determine more broadly how patients with dual sensory impairment are uniquely interacting with the healthcare system.

\section{Conclusions}

In summary, this study demonstrates that vision and dual sensory impairment are associated with greater odds of accompaniment to medical visits in a nationally representative sample of older adults. Given that accompaniment among older adults with sensory impairment is highly prevalent, these findings may have clinical significance for how physicians and other healthcare providers might engage, involve and communicate with 
patient companions. These findings also suggest that this accompaniment may be related to communication for those with hearing impairment and transportation for those with vision impairment. While the function and value of healthcare accompaniment for those with sensory impairments may differ, further work is needed to elucidate the roles, benefits, and differences of companions of older adults with sensory impairments. From a healthcare quality planning perspective, engaging companions in the medical visit may not only improve patient-provider communication, but may also improve compliance, adherence and healthcare outcomes. At a time when the COVID-19 pandemic is changing people's interaction with the healthcare system, it is imperative to take into account the accompaniment needs of people with sensory impairment and other groups who may be relying on their companions during medical visits.

\section{Abbreviations}

ADL: Activities of Daily Living; Cl: Confidence Interval; COVID-19: Coronavirus disease 2019; MCBS: Medicare Current Beneficiary Survey; OR: Odds Ratio; QMB: Qualified Medicare Beneficiary

\section{Acknowledgements}

Not applicable.

\section{Authors' contributions}

EP and YA organized the data. NR, AW, and BS conducted statistical analysis and data interpretation. NR and LA drafted the initial manuscript. All authors (NR, LA, EP, YA, AD, JD, AW, BS) were involved in the design and conception of the study, interpretation of results implications, and contributed to critical review and revision of the manuscript. The author(s) read and approved the final manuscript.

\section{Funding}

JD reports funding from National Institutes of Health/National Institute on Aging Grant (K01AG054693). NR reports funding from National Institutes of Health/National Institute on Aging Grant (K23AG065443). AW is supported by grants from the Commonwealth Fund (grant\# 20192345) and the Cochlear Center for Hearing and Public Health at the Johns Hopkins Bloomberg School of Public Health. The Funders had no role in the design, analysis, or interpretation of this project.

\section{Availability of data and materials}

The datasets used and analyzed during the current study are openly available to the public from the United States Centers for Medicare and Medicaid Services. https://www.cms.gov/Research-Statistics-Data-andSystems/Downloadable-Public-Use-Files/MCBS-Public-Use-File

\section{Ethics approval and consent to participate}

The study was exempt from institutional review board audit as the data used were publicly available and de-identified.

\section{Consent for publication}

Not applicable.

\section{Competing interests}

NR reports a non-financial relationship as a scientific advisory board member to SHOEBOX, Inc. and Good Machine Studio and consulting honoraria from Helen of Troy and BioMedical Insights. AW reports receiving a speaker honorarium from the American Speech-Language-Hearing Association and consulting honorarium from BioMedical Insights. No other competing interests from other authors are reported.

\section{Author details}

'Cochlear Center for Hearing and Public Health, Johns Hopkins University Bloomberg School of Public Health, 2024 E. Monument Street, Baltimore, MD 21205, USA. ${ }^{2}$ Department of Epidemiology, Johns Hopkins University Bloomberg School of Public Health, Baltimore, MD, USA. ${ }^{3}$ Wilmer Eye Institute, Johns Hopkins University School of Medicine, Baltimore, MD, USA. ${ }^{4}$ Department of Health Policy and Management, Johns Hopkins University Bloomberg School of Public Health, Baltimore, MD, USA.

Received: 3 June 2020 Accepted: 19 October 2020

Published online: 29 October 2020

\section{References}

1. Whitson HE, Lin FR. Hearing and vision care for older adults: sensing a need to update Medicare policy. JAMA. 2014;312(17):1739-40.

2. Vitale S, Cotch MF, Sperduto RD. Prevalence of visual impairment in the United States. JAMA. 2006;295(18):2158-63.

3. Goman AM, Lin FR. Prevalence of hearing loss by severity in the United States. Am J Public Health. 2016;106(10):1820-2.

4. Lin FR, Niparko JK, Ferrucci L. Hearing loss prevalence in the United States. Arch Intern Med. 2011;171(20):1851-2.

5. Swenor BK, Ramulu PY, Willis JR, Friedman D, Lin FR. The prevalence of concurrent hearing and vision impairment in the United States. JAMA Intern Med. 2013:173(4):312-3.

6. Goman AM, Reed NS, Lin FR. Addressing estimated hearing loss in adults in 2060. JAMA Otolaryngol Head Neck Surg. 2017:143(7):733-4.

7. Varma R, Vajaranant TS, Burkemper B, et al. Visual impairment and blindness in adults in the United States: demographic and geographic variations from 2015 to 2050. JAMA Ophthalmol. 2016;134(7):802-9.

8. Jiam NT, Li C, Agrawal Y. Hearing loss and falls: a systematic review and meta-analysis. Laryngoscope. 2016;126(11):2587-96.

9. Lin FR, Metter EJ, O'Brien RJ, Resnick SM, Zonderman AB, Ferrucci L. Hearing loss and incident dementia. Arch Neurol. 2011;68(2):214-20.

10. Mick P, Parfyonov M, Wittich W, Phillips N, Guthrie D, Kathleen P-FM. Associations between sensory loss and social networks, participation, support, and loneliness: analysis of the Canadian longitudinal study on aging. Can Fam Physician. 2018;64(1):e33-41.

11. Pronk M, Deeg DJ, Kramer SE. Hearing status in older persons: a significant determinant of depression and loneliness? Results from the longitudinal aging study Amsterdam. Am J Audiol. 2013;22(2):316-20.

12. Reed-Jones RJ, Solis GR, Lawson KA, Loya AM, Cude-Islas D, Berger CS. Vision and falls: a multidisciplinary review of the contributions of visual impairment to falls among older adults. Maturitas. 2013;75(1):22-8.

13. Swenor BK, Wang J, Varadaraj $\mathrm{V}$, et al. Vision impairment and cognitive outcomes in older adults: the health ABC study. J Gerontol A Biol Sci Med Sci. 2019;74(9):1454-60.

14. Chien W, Lin FR. Prevalence of hearing aid use among older adults in the United States. Arch Intern Med. 2012;172(3):292-3.

15. Willink A, Schoen C, Davis K. Consideration of dental, vision, and hearing services to be covered under Medicare. JAMA. 2017:318(7):605-6.

16. Saunders $\mathrm{GH}$, Echt KV. An overview of dual sensory impairment in older adults: perspectives for rehabilitation. Trends Amplif. 2007;11(4):243-58.

17. Schneider JM, Gopinath B, McMahon CM, Leeder SR, Mitchell P, Wang JJ. Dual sensory impairment in older age. J Aging Health. 2011;23(8): 1309-24.

18. Morse AR, Seiple W, Talwar N, Lee PP, Stein JD. Association of vision loss with hospital use and costs among older adults. JAMA Ophthalmol. 2019; 137(6):634-40.

19. Reed NS, Altan A, Deal JA, et al. Trends in health care costs and utilization associated with untreated hearing loss over 10 years. JAMA Otolaryngol Head Neck Surg. 2019:145(1):27-34.

20. lezzoni LI, Davis RB, Soukup J, O'Day B. Physical and sensory functioning over time and satisfaction with care: the implications of getting better or getting worse. Health Serv Res. 2004;39(6 Pt 1):1635-51.

21. Reed NS, Betz JF, Kucharska-Newton AM, Lin FR, Deal JA. Hearing loss and satisfaction with healthcare: an unexplored relationship. J Am Geriatr Soc. 2019:67(3):624-6.

22. lezzoni LI, Davis RB, Soukup J, O'Day B. Quality dimensions that most concern people with physical and sensory disabilities. Arch Intern Med. 2003;163(17):2085-92. 
23. Hoffman JM, Yorkston KM, Shumway-Cook A, Ciol MA, Dudgeon BJ, Chan L. Effect of communication disability on satisfaction with health care: a survey of medicare beneficiaries. Am J Speech Lang Pathol. 2005;14(3):221-8.

24. Clayman ML, Roter D, Wissow LS, Bandeen-Roche K. Autonomy-related behaviors of patient companions and their effect on decision-making activity in geriatric primary care visits. Soc Sci Med. 2005;60(7):1583-91.

25. Wolff JL, Boyd CM, Gitlin LN, Bruce ML, Roter DL. Going it together: persistence of older adults' accompaniment to physician visits by a family companion. J Am Geriatr Soc. 2012;60(1):106-12

26. Wolff $J L$, Roter DL. Family presence in routine medical visits: a metaanalytical review. Soc Sci Med. 2011;72(6):823-31.

27. Centers for Medicare \& Medicaid Services (CMS). MCBS 2015 Methodology Report. 2018. https:/wwww.cms.gov/Research-Statistics-Data-and-Systems/Research/MCBS/ Downloads/MCBS2015MethodReport508.pdf. Accessed 1 July 2018.

28. Adler GS. A profile of the Medicare current beneficiary survey. Health Care Financ Rev. 1994;15(4):153-63.

29. Centers for Medicare and Medicaid Services (CMS). 2015 Medicare Enrollment Section. https://www.cms.gov/Research-Statistics-Data-andSystems/Statistics-Trends-and-Reports/CMSProgramStatistics/2015/2015_ Enrollment.html. Accessed 1 Dec 2018.

30. Wolff $J L$, Roter DL. Older adults' mental health function and patientcentered care: does the presence of a family companion help or hinder communication? J Gen Intern Med. 2012;27(6):661-8.

31. Betancourt JR, Green AR, Carrillo JE, Ananeh-Firempong O 2nd. Defining cultural competence: a practical framework for addressing racial/ethnic disparities in health and health care. Public Health Rep. 2003;1 18(4):293-302.

32. Cudmore V, Henn P, O'Tuathaigh CMP, Smith S. Age-related hearing loss and communication breakdown in the clinical setting. JAMA Otolaryngol Head Neck Surg. 2017;143(10):1054-5.

33. Swenor BK, Munoz B, West SK. A longitudinal study of the association between visual impairment and mobility performance in older adults: the Salisbury eye evaluation study. Am J Epidemiol. 2014;179(3):313-22.

34. Spencer C, Frick K, Gower EW, Kempen JH, Wolff JL. Disparities in access to medical care for individuals with vision impairment. Ophthalmic Epidemiol. 2009;16(5):281-8.

35. Epstein RM, Street RL Jr. The values and value of patient-centered care. Ann Fam Med. 2011;9(2):100-3.

36. Ryan LH, Smith J, Antonucci TC, Jackson JS. Cohort differences in the availability of informal caregivers: are the boomers at risk? Gerontologist. 2012;52(2):177-88

37. Wallhagen MI, Reed NS. Implications of hearing care policy for nurses. J Gerontol Nurs. 2018;44(9):9-14

38. Wolff $J$, Guan $Y$, Boyd CM, et al. Examining the context and helpfulness of family companion contributions to older adults' primary care visits. Patient Educ Couns. 2017;100(3):487-94.

39. Greene MG, Majerovitz SD, Adelman RD, Rizzo C. The effects of the presence of a third person on the physician-older patient medical interview. J Am Geriatr Soc. 1994:42(4):413-9.

40. Centers for Disease Control and Prevention (CDC). Coronavirus Disease 2019 (COVID-19) - Healthcare Facility Guidance. https://www.cdc.gov/ coronavirus/2019-ncov/hcp/guidance-hcf.html. Accessed 9 May 2020.

\section{Publisher's Note}

Springer Nature remains neutral with regard to jurisdictional claims in published maps and institutional affiliations.

Ready to submit your research? Choose BMC and benefit from:

- fast, convenient online submission

- thorough peer review by experienced researchers in your field

- rapid publication on acceptance

- support for research data, including large and complex data types

- gold Open Access which fosters wider collaboration and increased citations

- maximum visibility for your research: over $100 \mathrm{M}$ website views per year

At BMC, research is always in progress.

Learn more biomedcentral.com/submissions 